\title{
PERFORMANCE OF BLENDED CORROSION INHIBITORS FOR REINFORCED CONCRETE
}

\author{
Sabih Akhtar ${ }^{1}$ \\ ${ }^{I}$ Associate Professor, Department of Civil Engineering, AMU, Aligarh, U.P.-202002
}

\begin{abstract}
Use of chemical corrosion inhibitors has been recognized as one of the effective way of controlling rebar corrosion in reinforced cement concrete (RCC). Corrosion inhibiting admixtures fall into the specialty admixture category and are used to slow down corrosion of reinforcing steel in concrete. The addition of corrosion inhibitors to the mix, offers a viable corrosion protection measure. There are generally three groups of inhibitors: anodic, cathodic and mixed inhibitors. The effect of these chemicals on various physical properties of cement such as setting time, $\mathrm{pH}$, and compressive strength needs to be explored before use. In the present investigation an attempt has been made to mix two commercially available corrosion inhibitors and evaluate its effect on setting time, $\mathrm{pH}$ and compressive strength. In the next part of the study electrochemical test involving the blended chemical corrosion inhibitor were also conducted on RCC slab specimen. Corrosion kinematic parameters have been estimated using potentio-dynamic polarization tests. It has been observed that the corrosion inhibitor does not have any adverse effect on physical properties of cement and cement concrete. The low corrosion current density exhibited by the inhibitor proves their potential in controlling corrosion initiation and propagation.
\end{abstract}

Keywords - Corrosion inhibitors, setting time, compressive strength, corrosion kinematic parameters

\section{INTRODUCTION}

Reinforced concrete is a very versatile construction material. Properly designed concrete structures are both strong and durable. However, concrete structures are vulnerable to a number of factors that can cause deterioration. Deterioration can result in loss of strength and unsafe conditions. Therefore it is important to have an understanding of the vulnerabilities of concrete structures in order to help minimize long-term repair and maintenance costs.

Concrete deterioration typically occurs when the material is exposed to weather, water or chemicals over an extended period of time. When protected from these elements, as in the case of internal members of enclosed commercial and institutional buildings, reinforced concrete can be expected to perform for decades with very little maintenance. However, in many cases, concrete can be exposed to environments that promote deterioration. Examples of these types of environments include parking garages, exterior balcony slabs, and industrial structures where the concrete is exposed to process chemicals. Long-term deterioration can occur at the embedded reinforcing steel as well as at the exposed concrete surface.

The deterioration of reinforced cement concrete is due to the corrosion of the reinforcing steel has become a major problem. It has received worldwide attention and code of practices of different countries has suggested measures to control the steel corrosion but evidence of corrosion of steel in concrete continues to be reported in field situations. The corrosion of steel reinforcement in concrete structures leads to concrete fracture, loss of bond between steel and matrix and reduction in strength and ductility. As a result, safety, serviceability and durability of concrete structures are reduced.

During the last few decades the corrosion problem in reinforced concrete has been extensively investigated by many researchers. Corrosion inhibitors are one of the most cost-effective solutions to rebar corrosion problem in concrete. Corrosion inhibiting admixtures fall into the specialty admixture category and are used to slow down corrosion of reinforcing steel in concrete. In order to protect metallic materials against corrosion, certain inorganic and organic products, called corrosion inhibitors, are added in small concentration to the aggressive medium [1]. The addition of corrosion inhibitors to the mix, offers a viable corrosion protection measure There are generally three groups of inhibitors: anodic, cathodic and mixed inhibitors. Anodic inhibitors reduce the corrosion rate by reacting with the corrosion products and form a protective film. Cathodic inhibitors reduce the corrosion rate by reacting with the cathode sites (as an oxygen-barrier) on the steel. Passivating inhibitors like nitrites represent special types of anodic inhibitors and they are generally very effective if present in sufficient concentrations. Mixed inhibitors both influence the anodic and cathodic reaction sites, by forming an adsorption film on the metal surface. These adsorption type inhibitors are typically organic compounds [2-3].

In recent years, results of many investigations and review articles have been published on organic migrating corrosion inhibitor (MCI), which is mainly composed of an amino carboxylate or amino alcohol. The inhibitors are either admixtured or directly applied to the concrete surface and they act under bipolar mechanism and penetrate even dense concrete by virtue of their vapour pressure and affinity for 
the embedded steel in concrete. Water based mixtures of amines and esters were supposed to form a protective organic layer on the steel bars through a chelation process. The addition of corrosion inhibitors to the mix, offers a viable corrosion protection measure [4-5].

Rosenberg and Gaidis [6] have investigated the inhibition performance of calcium nitrite in simulated concrete pore solution by potentio-dynamic polarisation study and found that calcium nitrite increased the breakdown potential for carbon steel in chloride containing saturated $\mathrm{Ca}(\mathrm{OH})_{2}$ solution. Berke [7] also presented similar results. Neagle [8] proved the effectiveness of some organic corrosion inhibitor through electrochemical tests. Dillard [9] found that the sodium tetra borate inhibitor forms a protective layer on metal surface through the reaction of borate and oxygen, but it directly depends on $\mathrm{pH}$ of the pore solution. SagoeCrentsil, Yilmaz and Glasser [10] have found that the water soluble carboxylic acid is an effective inhibitor in presence of $2.5 \%$ chloride contamination. A series of laboratory trials were undertaken to assess the corrosion inhibitor under chloride condition [11]. A study by [12] using the calcium nitrite in cement paste pore solution containing sodium chloride by potentio-dynamic polarization method revealed that the passivity break down at a lower potential in the inhibited solution.

In the present study, an attempt has been made to investigate the behaviour of the blend of two corrosion inhibitors viz. Calcium Nitrite and Calcium Hypophosphite added in equal quantity. Physical properties tests of the cement and concrete in the presence of these inhibitors and potentiodynamic polarization tests were conducted.

\section{EXPERIMENTAL INVESTIGATIONS}

The effect of chosen corrosion inhibitors on setting time, $\mathrm{pH}$ and compressive strength has been studied. In the next part of the study electrochemical test involving these chemical corrosion inhibitors were also conducted.

\subsection{Setting Time Test}

Setting time tests were carried out as per the recommendations of the IS: 4031(Part 5) [13] using 43Grade Ordinary Portland cement. In Blank (control) specimen, no inhibitor was mixed. $3 \%$ dose of the blended inhibitor by weight of the cement was used. The setting time values are given in Table- 1 .

\subsection{Test for $\mathrm{pH}$}

$p H$ is another important parameter governing the corrosion and its propagation. Four different mediums were taken for this part of the study. Tests were conducted for both potable and distilled water at a constant temperature of $28 \pm 2{ }^{\circ} \mathrm{C}$ and the results are tabulated in Table- 2 .

\subsection{Compressive Strength Test}

To investigate the effect of corrosion inhibitors on the compressive strength of mortar, the mortar cubes of size
$70.6 \times 70.6 \times 70.6 \mathrm{~mm}$ were tested after $3,7,14$ and 28 days of curing as per the recommendations of IS: 4031(Part 6). Effect of corrosion inhibitors on compressive strength of cement concrete (mix ratio1:2:4) were also determined by testing standard cube of size $150 \times 150 \times 150 \mathrm{~mm}$, Results has been presented in Tables 3-4.

\subsection{Electrochemical Test}

Electrochemical studies (Tafel extrapolation and AC impedance tests) were also undertaken. Electrochemical System Model "Gill AC" (500 mA/ 100 kHz/ Guard Ring of ACM instruments, U.K.) was used for these experiments. The instrument had inbuilt software support to evaluate corrosion kinetic parameters. The experiments were carried out at a constant temperature of $28 \pm 2{ }^{\circ} \mathrm{C}$. The test specimens are shown in Figs.1-2. The test specimens were prepared using river sand (fineness modulus - 2.6) and coarse aggregate (fineness modulus - 4.8). Blended corrosion inhibitor dose of $3 \%$ was used. An inhibitor free test specimen was also prepared to serve as control. Both the categories of test specimens were subjected to alternate wetting and drying cycles of one week duration each. Specimens were tested after an exposure of 72 weeks. The result of the electrochemical tests is presented in Figs.3-6.

\section{DISCUSSION ON TEST RESULTS}

The results of the setting time of the cement after adding 3\% dose of the inhibitors are given in Table - 1. It has been observed that the initial and final setting time are reduced to some extent, however the values remains within the permissible limits of the codal provisions.

The effect of addition of inhibitors on $\mathrm{pH}$ has been tabulated in Table - 2. 3\% concentration of the blended inhibitor increases the $p H$ value marginally. It is interesting to note that when the inhibitor was tested in cement slurry condition the value of $p H$ rose to around 12 , which is considered to be fairly alkaline.

The results of mortar and concrete cube compressive strength are given in Tables 3-4. Due to the addition of 3\% dose of blended inhibitor the compressive strength has been observed to be more than the control throughout the observation period.

The results of the electrochemical test are presented with the help of Tafel plots, Nyquist, Bode and Theta plots (Figs.36). Reasonably low corrosion current density thereby lower corrosion rates as compared to the blank specimen are clear indicator of the effectiveness of both the blended inhibitor.

\section{CONCLUSION}

Properties investigated viz. Setting time, $p H$ and compressive strength tests clearly indicate that the addition of the blended inhibitors do not have any adverse effect. The low corrosion current density exhibited by the inhibitor proves their potential in controlling corrosion initiation and propagation. Long term studies with varying dose of 
corrosion inhibitors are needed for making final recommendations with regard to the dose of these inhibitors for the protection of steel reinforcement in concrete.

\section{REFERENCES}

[1] Fontana, M.G., "Corrosion Engineering”, McGrawHill book Company, 1987.

[2] Harrop, D., "Chemical inhibitors for Corrosion Control", Proceedings of International Symposium at the University of Manchester, Royal Society of Chemistry, Special publication No.71, London, U.K., 4-20, 1988.

[3] El-Jazairi, B. and Berke, N.S., "The Use of Calcium Nitrite as a Corrosion Inhibiting Admixture to Steel Reinforcement in Concrete", Elsevier Applied Science, London and New York, U.S.A., 571-585, 1990.

[4] Berke, N.S., "A review of Corrosion Inhibitor in Concrete", Material Performance, 28(10), 41-44, 1989.

[5] West, J.M., "Electro-deposition and Corrosion Processes", Van Nostrand Reinhold Co., New York, U.S.A., 138-148, 1971.

[6] Rosenberg, A.M. and Gaidis, J.M. (1979) - The Mechanism of Nitrite Inhibition of Chloride Attack on Reinforcing Steel in Alkaline Aqueous Environments, Materials Performance, 18 (11), 4548.

[7] Berke, N.S. (1986) - The Use of Anodic Polarisation to Determine the Effectiveness of Calcium Nitrite as an Anodic Inhibitor, Corrosion effect of Stray Currents and the Techniques for Evaluating Corrosion of Rebars in Concrete, ASTM STP 906, Ed.: V. Chaker, ASTM, Philadelphia, 78-91.

[8] Neagle, W. (1991) - Corrosion Inhibition, Chemical Abstracts, 177, 1.

[9] Dillard, J.G. (1991) - Migration of Inhibition in Aqueous Solution through Concrete, Transportation Research Record No. 30, Washington, D.C., Transportation Research Board National Research Council, U.S.A.

[10] Sagoe-Crentsil, K.K, Yilmaz, V.T. and Glasser, F.P. (1993) - Corrosion Inhibition of Steel in Concrete by Carboxylic Acid, Cement and Concrete Research, 23, 1380-1388.

[11] Mackechnie, J.R., Rylands, T. and Alexander, M.G. (1999) - Laboratory Trials with Organic Corrosion Inhibitor, Proceedings $14^{\text {th }}$ International Corrosion Congress (ICC), Corrosion Institute of Southern Africa, Kelvin, R.S.A, 890-898.

[12] Tullumin, M., Mammolitie, L., Sodhi, R., Hannsson C.M. and Hope, B.B. (1995) Passivation of Reinforcing Steel Exposed to Synthetic Pore Solution and the Effect of Calcium Nitrite Inhibitor, Cement and Concrete Aggregate, 17, 34.

[13] IS: 4031, Part 5 and 6, "Indian Standard Specification Methods of Physical Tests for Hydraulic Cement", BIS, New Delhi, India, 1988.

Table - 1: Effect of Corrosion Inhibitor on Setting Time of Cement

\begin{tabular}{|l|l|l|}
\hline System & $\begin{array}{l}\text { Initial Setting Time } \\
(\text { minutes })\end{array}$ & Final Setting Time (minutes) \\
\hline Blank & 103 & 325 \\
\hline $3 \%$ dose blended corrosion inhibitor & 87 & 296 \\
\hline
\end{tabular}

Table- 2: Effect of Corrosion Inhibitor on $\mathrm{pH}$

\begin{tabular}{|l|l|l|}
\hline System & $p H$ in Potable water & $\begin{array}{l}p H \text { in Distilled } \\
\text { water }\end{array}$ \\
\hline Blank & 7.5 & 7.3 \\
\hline Cement (Slurry) & 12.2 & 12.2 \\
\hline 3\% dose blended corrosion inhibitor & 7.6 & 7.5 \\
\hline $3 \%$ dose blended corrosion inhibitor + Cement (Slurry) & 12.2 & 12.0 \\
\hline
\end{tabular}

Table - 3: Effect of Corrosion Inhibitor on Compressive Strength of Mortar Cube

\begin{tabular}{|l|l|l|l|l|}
\hline \multirow{2}{*}{ Specimen Description } & \multicolumn{4}{|l|}{ Compressive Strength of Mortar Cube in N/mm ${ }^{2}$} \\
\cline { 3 - 6 } & 3 days & 7 days & 14 days & 28 days \\
\hline Blank & 20.1 & 25.5 & 30.0 & 43.2 .0 \\
\hline $\begin{array}{l}3 \% \text { dose blended corrosion } \\
\text { inhibitor }\end{array}$ & 21.4 & 27.9 & 35.0 .0 & 48.1 \\
\hline
\end{tabular}

Table - 4: Effect of Corrosion Inhibitor on Compressive Strength of Cement Concrete (Mix 1:2:4)

\begin{tabular}{|l|l|l|}
\hline \multirow{2}{*}{ Specimen Description } & \multicolumn{2}{|l|}{ Compressive Strength of Concrete Cube in N/mm } \\
\cline { 2 - 3 } & 7 days & 28 days \\
\hline Blank & 15.5 & 22.2 \\
\hline $3 \%$ dose blended corrosion inhibitor & 16.4 & 26.1 \\
\hline
\end{tabular}




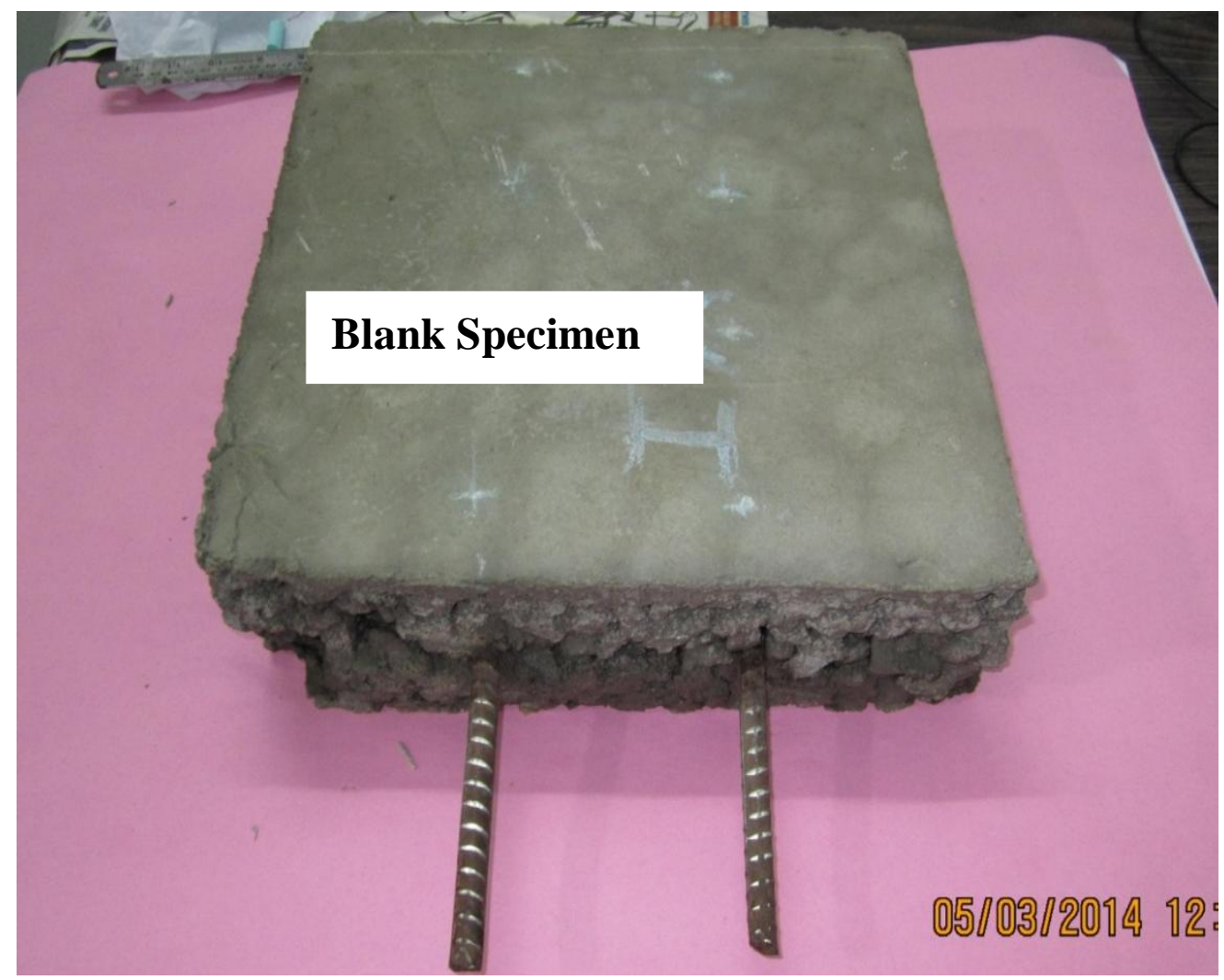

Fig. 1: Control specimen

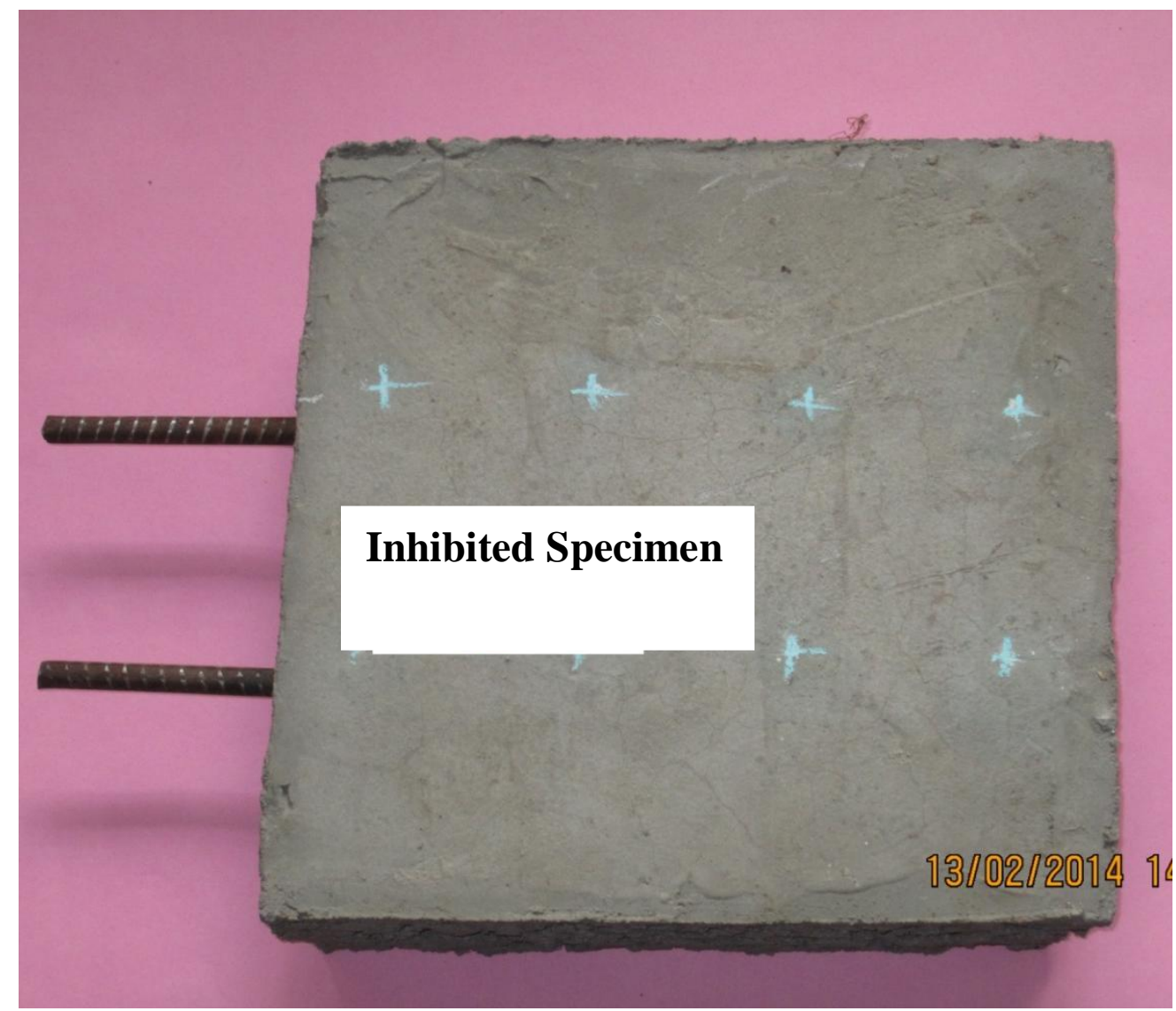

Fig. 2: Inhibited specimen 


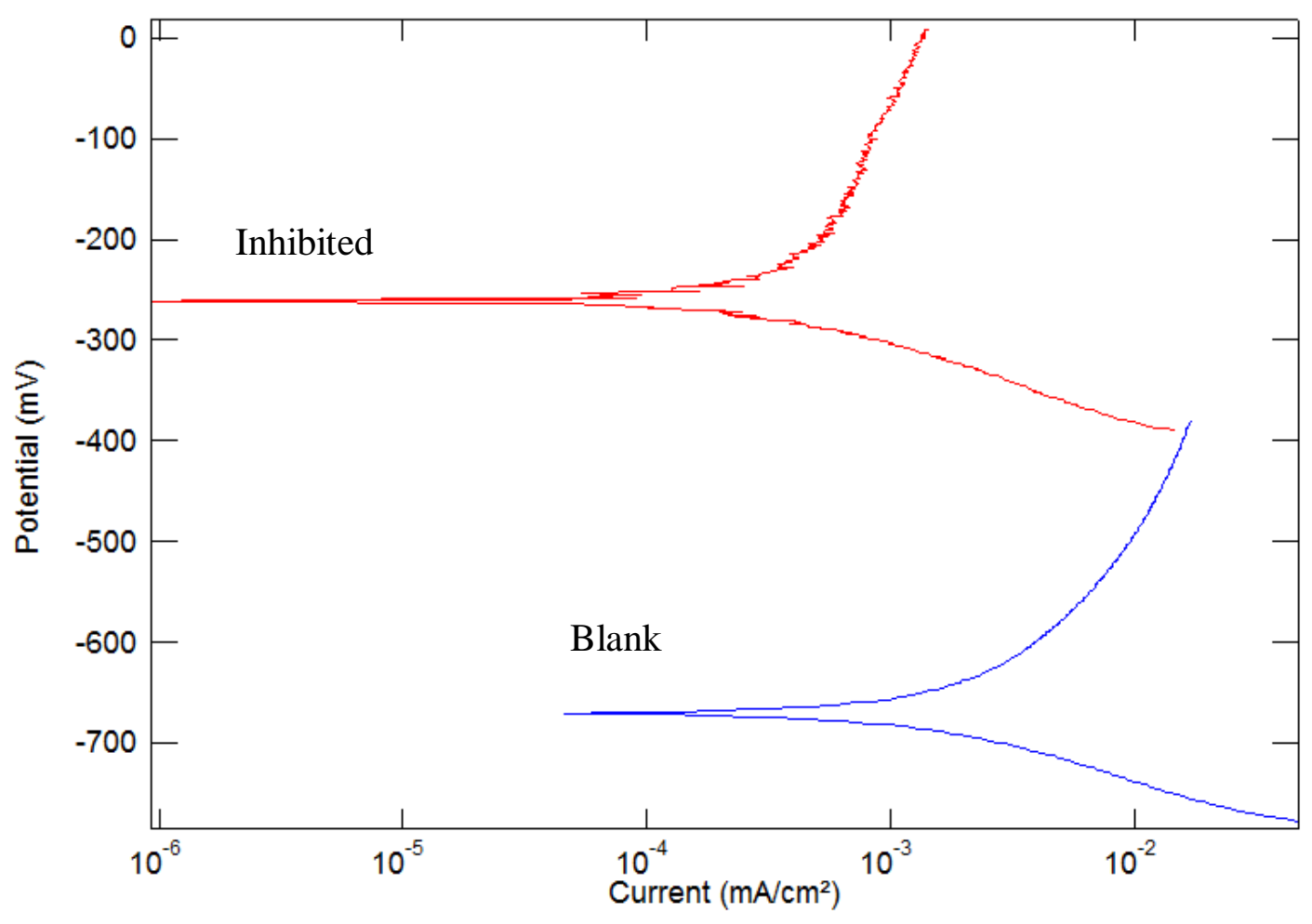

Fig. 3: Tafel Plot for the Control and the inhibited specimen

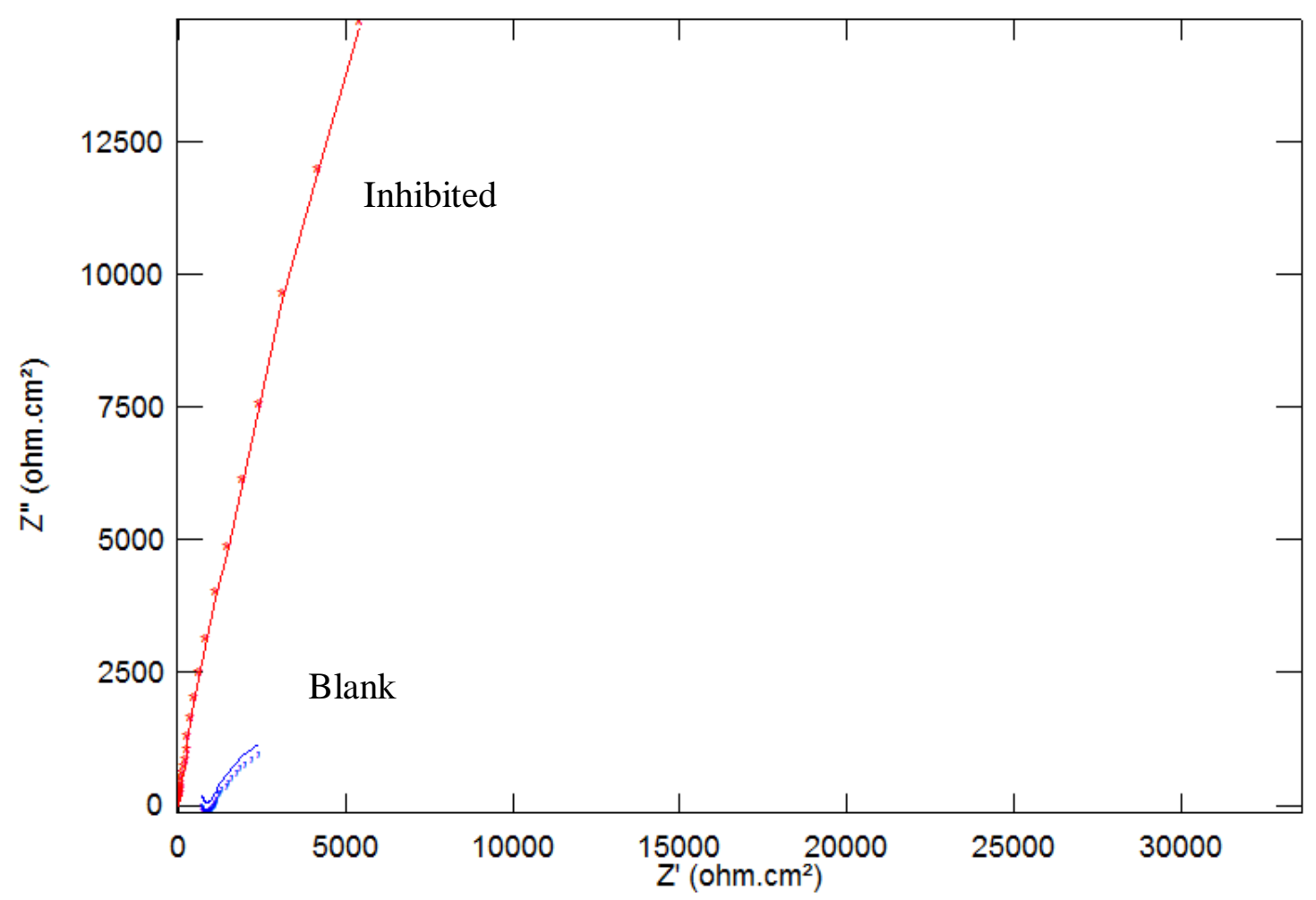

Fig. 4: Nyquist Plot for the Control and the inhibited specimen 


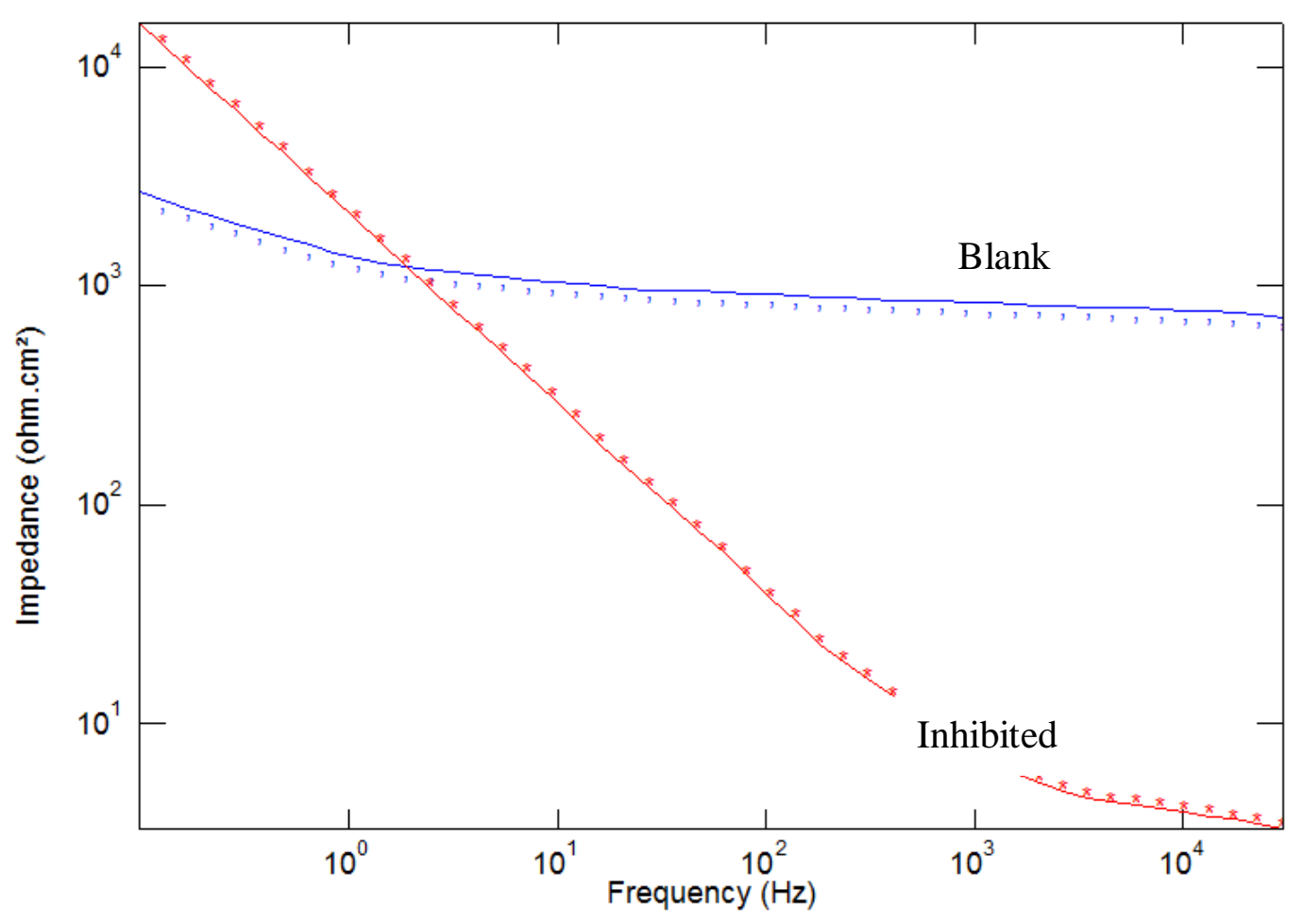

Fig. 5: Bode plot for the Control and the inhibited specimen

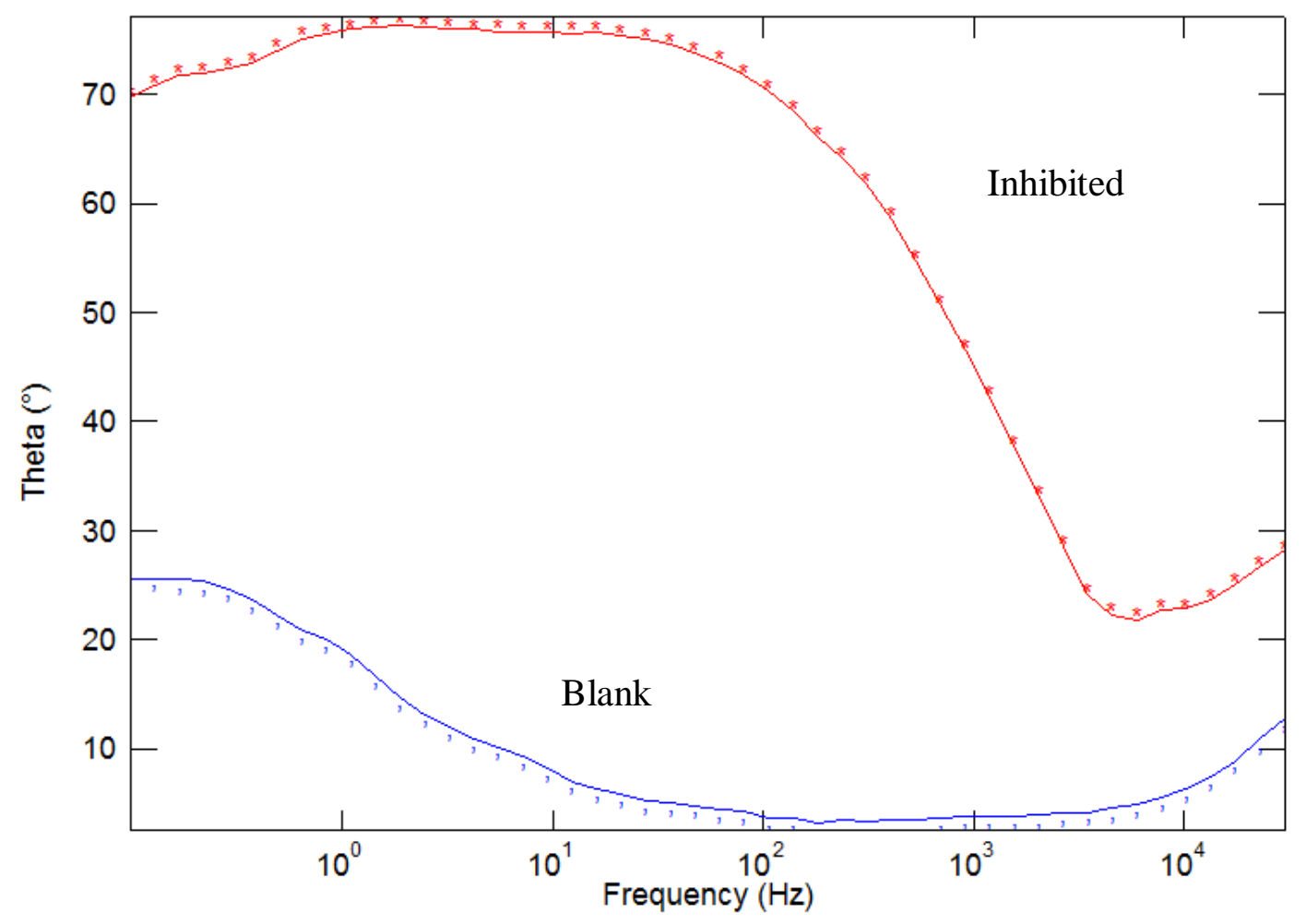

Fig. 6: Theta plot for the Control and the inhibited specimen 